Territorios 33 / Bogotá, 2015, pp. 83-102

ISSN: 0123-8418

ISSNe: 2215-7484

Procesos de ocupación del territorio, historia urbana y patrimonio II

\title{
Estrategias patrimoniales y turísticas: su incidencia en la configuración urbana. El caso Rosario, Argentina
}

Patrimonial and Tourist Strategies: His Incident in the Urban Configuration. The Case of Rosario, Argentina

Estratégias patrimoniais e turísticas: sua incidência na configuração urbana. O caso Rosário, Argentina

Paula Vera*

Recibido: 15 de septiembre de 2014

Aprobado: 24 de abril de 2015

Doi: dx.doi.org/10.12804/territ33.2015.04

Para citar este artículo:

Vera, P. (2015). Estrategias patrimoniales y turísticas: su incidencia en la configuración urbana. El caso Rosario. Territorios, 33, 83-101. doi: dx.doi.org/10.12804/territ33.2015.04

* Doctora en Ciencias Sociales y Humanas por la Universidad Nacional de Quilmes, Licenciada en Comunicación Social por la Universidad Nacional de Rosario. Becaria postdoctoraldel Consejo Nacional de Investigaciones Cientificas y Técnicas (CONICET). Correo electrónico: paulavera. arg@gmail.com. 
Palabras clave

Patrimonio cultural, turismo, imaginario urbano, marca ciudad, reconfiguración urbana, Rosario.

Keywords

Cultural heritage, tourism, urban imaginary, city marks, urban reconfiguration,

Rosario.

Palavras-chave

Patrimônio cultural, turismo, imaginário urbano, marca cidade, reconfiguração urbana,

Rosário.

territarias 33

84

\section{RESUMEN}

En este artículo se analizan las estrategias turísticas y de valoración patrimonial y su incidencia en la configuración urbana. Una de las hipótesis es que esas estrategias se fundamentan en el imaginario urbano dominante que implica, tanto un campo de sentidos sobre un pasado - construido, imaginado e instituido - como sobre un presente y un futuro donde todo parece convivir en armonía, como si la imagen de la ciudad fuera única, coherente y compartida por todos. En tal sentido, el objetivo es realizar una aproximación a las relaciones materiales y simbólicas entre los aspectos patrimoniales y turísticos y analizar cómo inciden en los procesos de configuración urbana. Para ello, se abordan las trayectorias de estas problemáticas desde las políticas públicas en la ciudad de Rosario, cuándo emergen en las discursividades oficiales y cómo se plasman en el territorio, empleando una estrategia metodológica cualitativa y una perspectiva crítica enmarcada en el campo de los estudios culturales urbanos.

\section{ABSTRACT}

In this article we analyze the tourism strategies and heritage valuation and their impact on urban configuration. One of the hypotheses is that those strategies are based on the dominant urban imaginary that implies a field of meanings about the past — built, imagined and instituted — as a present and a future where everything seems to live in harmony as if the image of the city was unique, coherent and shared by all. In this sense, the aim is to approach the material and symbolic relations between the heritage and tourism aspects and analyze how they affect the processes of urban settings. For it, we approached the paths of these problematic from the public policies in Rosario's city, when they emerge in official discourse and how are reflected in the territory. We use a qualitative methodological strategy and a critical perspective placed in the field of urban cultural studies.

\section{RESUMO}

Neste artigo analisam-se as estratégias turísticas e de valoração patrimonial e a sua incidência na configuração urbana. Uma das hipóteses é que essas estratégias se fundamentam no imaginário urbano dominante que implica tanto um campo de sentidos sobre um passado — construído, imaginado e instituído- quanto sobre um presente e um futuro onde tudo parece conviver em harmonia como se a imagem da cidade fosse única, coerente e partilhada por todos. Em tal sentidos, o objetivo é realizar uma aproximação às relações materiais e simbólicas entre os aspectos patrimoniais e turísticos e analisar como incidem nos processos de configuração urbana. Para isso, abordam-se as trajetórias destas problemáticas desde as políticas públicas na cidade de Rosário, quando emergem nas discursividades oficiais e como se plasmam no território, empregando uma estratégia metodológica qualitativa e uma perspectiva crítica enquadrada no campo dos estudos culturais urbanos. 


\section{Introducción}

Tanto la ciudad como el patrimonio son productos de complejos procesos de construcción social y, como tales, son dinámicos, variables, mutables e inestables. Como punto de partida general, se sostiene que los procesos de construcción social de lo urbano se sustentan en el entramado de sentidos que esa misma sociedad ha venido construyendo a lo largo de su historia y, a partir de él, determina, en cada momento, qué cosas tienen valor y cuáles no. Los imaginarios sociales conforman la trama significativa sobre la que se funda la construcción de la sociedad y de la realidad. Estos se materializan en diversas acciones, afectos, representaciones, discursos, imágenes, objetos, instituciones, leyes y valores. Entonces, se entiende por imaginario no lo inventado, fantasioso o inexistente, sino aquella capacidad de crear significaciones y representaciones. Es decir, la facultad del hombre de crear su mundo y conferirle sentido (Castoriadis, 2003).

En relación con la problemática abordada en este trabajo, las estrategias turístico-patrimoniales y su incidencia en la configuración urbana, se puede afirmar que lo que cobra valor patrimonial para una sociedad puede variar en el tiempo e, incluso, ser diferente para distintos sectores sociales, pero siempre está vinculado al imaginario social instituido. Para analizar estos procesos de construcción de sentido sobre lo urbano y lo patrimonial se puede recurrir a dos estrategias. Por un lado, indagar los imaginarios urbanos al rescatar la perspecti- va subjetiva de los ciudadanos (Silva, 2006; García Canclini, 2007) o, como en el caso de este estudio, examinar los imaginarios dominantes desde la perspectiva de las discursividades oficiales, abarcando los discursos de planes urbanos y políticas públicas, decretos e intervenciones sobre el espacio, entre otras. Esta elección se fundamenta en que los gobiernos, a partir de su potestad normativa y ejecutiva, inciden de manera determinante en lo que se considera, muestra y construye como patrimonio para una sociedad. Es importante destacar que el patrimonio cultural es construido socialmente a partir de símbolos revestidos de cierta legitimidad y por eso resultan aceptados, consolidando así imágenes, objetos, creencias e historias en el imaginario colectivo hegemónico (Berger \& Luckmann, 2008; Castoriadis, 2003).

En las últimas décadas, se ha ido profundizando la centralidad que adquirió lo local como motor del desarrollo o despegue económico de las ciudades de diversas escalas (Castells, 1997). Esto implicó, no solo mayor injerencia de los gobiernos locales en la diagramación, planificación y ejecución de políticas públicas, sino también la búsqueda de estrategias para dinamizar las economías urbanas. En este contexto, tomaron fuerza las creencias que dan sustento al urbanismo neoliberal que, aferrado a la planificación estratégica, convenios urbanísticos público-privados, proyectos de urbanización de alta gama y promoción de la economía de servicios, tienden a transformar la ciudad sobre la base de intereses concretos, que generalmente no responden territarias 33

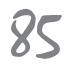


${ }^{1}$ Una primera aproximación a este tema se publicó como artículo en Revista Bitácora Urbano Territorial, en el año 2013 con el nombre de "Nuevas ciudades turísticas: imaginarios urbanos y procesos de urbanización. El caso de Rosario, Argentina”.

\section{territarias 33}

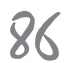

a las necesidades de las mayorías o de los sectores menos favorecidos (Harvey, 2008; Theodore, Peck \& Brenner, 2009). En este sentido, una de las consecuencias que pueden visualizarse en las ciudades contemporáneas es la importación de modelos urbanos, ideas y mecanismos que producen la homogeneización de paisajes urbanos y una fragmentación creciente.

Al mismo tiempo, con el objetivo de posicionarlas como productos dentro del mercado mundial, en tanto ciudades de negocios, de turismo, cultura o innovación se están desarrollando marcas de ciudad que condensan imágenes y valores para la transformación del modelo económico urbano (Lury, 2007). No obstante, definir qué ciudad ser y a qué mercado ingresar a competir es difícil, ya que los requerimientos actuales demandan satisfacer más de una exigencia a la vez. Al mismo tiempo, la conformación de la ciudad como producto implica estrategias de marketing para construir una marca de ciudad vendible, soportada en ciertos rasgos de identidad que, en paralelo a las estrategias de venta hacia el exterior, precisan también estrategias de promoción, cohesión e identificación hacia el interior. Este marco, en donde lo cultural se fue tornando un valor de competitividad funcional al desarrollo de las ciudades como productos de consumo (Dwyer \& Kim, 2003; Harvey, 1990; Lash \& Urry, 1998; Ritchie \& Crouch, 2003;), resulta adecuado para la intersección de dos fenómenos que se constituyen como claves de la pretendida competitividad que los gobiernos locales buscan para desarrollar sus estrategias de marketing: la promoción del turismo urbano y la revalorización del patrimonio de la ciudad.

El fenómeno del turismo urbano introduce a las ciudades en una disputa por atraer flujos de capital incentivando el empleo de estrategias del marketing en la gestión de los gobiernos locales (Benko, 2000; Castells, 1997; Delgado, 2010; Harvey, 1990; Judd, 2003). Este fenómeno se acentúa más aún en ciudades sin tradición turística, que deben desarrollar tácticas para hacerse conocer, construir productos atractivos y generar el interés del turista. Las nuevas ciudades turísticas no solo deben convencer al entorno nacional e internacional de sus atributos para recibir visitantes, sino también a los propios habitantes. ${ }^{1}$

En simultáneo, se comprueba un proceso de resignificación de lo patrimonial como producto de valor que también puede mejorar la competitividad y los procesos de turistificación de las ciudades. Diversos autores han trabajado sobre la retroalimentación de estos fenómenos en las urbes contemporáneas (Delgado, 2010; Calle \& García, 1998; Prats, 1998). La selección de determinados símbolos patrimonializables expone la tensión de preservar algunas huellas y testimonios que permitan dar cuenta de cierto pasado dentro del reservorio inagotable de signos, objetos y relatos que es la ciudad (Pesavento, 1995). Esto conduce a pensar en dos aspectos. En primer lugar, desde un enfoque vinculado a las industrias culturales, se prestará atención a la retroalimentación que se genera entre turismo y patrimonio. Esta retroalimen- 
tación se hace evidente si se piensa que el patrimonio cultural, al constituirse como atractivo turístico, hace de las actividades culturales productos más competitivos. $\mathrm{Al}$ mismo tiempo, el turismo, al estimular la conservación, rehabilitación y construcción de circuitos y objetos patrimoniales, como activos para su explotación, funciona como marco ideológico que tiene la capacidad de adaptar la cultura y la naturaleza según sus necesidades (Maccannell, 2007). En segundo lugar, es necesario reflexionar acerca del público al que se orienta la selección de signos identitarios. En este sentido, se puede apreciar que existen dos destinatarios. Por un lado, el propio habitante de la ciudad que aprueba y legitima esa representación del pasado. Por otro, el visitante, el turista, ese otro que consume determinados restos o fragmentos de historia.

Pero, ¿qué lugar simbólico y material ocupan los aspectos patrimoniales en los procesos de construcción de una nueva ciudad turística? ¿Es el turismo urbano un condicionante de las imágenes del pasado que se quiere preservar? ¿Inciden estas relaciones en los procesos de construcción y reconversión urbana?

Una de las hipótesis de este trabajo es que las estrategias patrimoniales y turísticas se fundamentan en el imaginario urbano dominante que implica, tanto un campo de sentidos sobre un pasado - construido, imaginado e instituido- como sobre un presente y un futuro donde todo parece convivir en armonía, como si la imagen de la ciudad fuera única, coherente y compartida por todos. En esta construcción simbó- lica radica una de las claves representacionales del discurso oficial como legitimador de cierto pasado y guardián de los anhelos que se presentan como colectivos.

El objetivo de este artículo es realizar una aproximación a las relaciones materiales y simbólicas, entre los aspectos patrimoniales y turísticos, y analizar cómo inciden en los procesos de configuración urbana. Por lo tanto, se abordan las trayectorias de las problemáticas del patrimonio y las estrategias de desarrollo del turismo urbano desde las políticas públicas en la ciudad de Rosario, ${ }^{2}$ cuándo emergen en las discursividades oficiales y cómo se plasman en el territorio. Para ello, se emplea una estrategia metodológica cualitativa y una perspectiva crítica enmarcada en el campo de los estudios culturales urbanos.

\section{Patrimonio y turismo: políticas convergentes}

La política de modernización estatal local se inicia con la gestión del socialismo en 1995. En 1998 se lanza lo que sería la hoja de ruta para la transformación de la ciudad: el Plan Estratégico Rosario (PER). La continuidad de esta gestión permitió la actualización del plan en 2010, bajo la denominación Plan Estratégico Rosario Metropolitano (PERM); complementado por el Plan Urbano Rosario 2007-2017 (PUR), que también tiene lineamientos estratégicos sobre diversos aspectos que afectan a la ciudad, entre ellos se destaca la recualificación de la zona costera y los espacios estratégicos a jerarquizar, mediante convenios público-privados, y el
${ }^{2}$ Rosario es una metrópolis del interior de Argentina que se encuentra en la zona central, $300 \mathrm{~km}$ al norte de la ciudad de Buenos Aires en la provincia de Santa Fe. Actualmente tiene 1193605 habitantes y una densidad de 631,5 habitantes $/ \mathrm{km}^{2}$; es la tercera ciudad de la Argentina, en relación con la cantidad de habitantes, y la mayor ciudad de la Provincia de Santa Fe, con una población total de 3199537 habitantes y una densidad de 24 habitantes $/ \mathrm{km}^{2}$ (Instituto Nacional de Estadísticas y Censos (INDEC), Censo 2010).

\section{territarias 33}

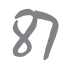


Plan de Desarrollo de Turismo Sustentable 2010- 2018 (PDTS).

En este proceso, la problemática del patrimonio se institucionaliza en la Municipalidad de Rosario en 1996 con la creación del Programa Municipal de Preservación del Patrimonio Urbano y Arquitectónico, a partir del cual se establecieron nuevas normativas y acciones tendientes a preservar y rehabilitar fundamentalmente patrimonio arquitectónico de la ciudad. Es interesante poner en relieve el interrogante sobre cómo se relaciona esta emergencia de lo patrimonial con la idea de preservar a los inmuebles de posibles demoliciones. En base al primer acercamiento a la problemática, se considera que la construcción de este programa no está tan ligada a los peligros de demolición como a las teorías y discursos de los noventa, relacionados con los nuevos gobiernos locales y las potenciales fuentes de desarrollo económico que se postulaban. Si bien, no existen datos oficiales de la década del noventa, a partir de 2000, el Instituto Provincial de Estadísticas y Censos (IPEC) elaboró un índice de permisos de construcción que permite cotejar la evolución de la actividad en la ciudad. Allí se puede corroborar que el auge inmobiliario, con las consecuentes demoliciones en masa, se inicia en 2003 y tiene su pico más alto entre 2006 y 2008 (Fundación Banco Municipal de Rosario, 2012). Esto nos permite suponer que las acciones públicas sobre el patrimonio no surgen principalmente para preservar la historia local de un avance de la construcción porque en los noventa esta actividad se encontraba estacionada.
Sin embargo, a inicios de este siglo, la preservación patrimonial se vuelve, al mismo tiempo, un obstáculo para una ciudad que pretende ser y mostrarse moderna, vanguardista y con gran actividad. Se puede, entonces, encontrar una primera controversia en torno a lo patrimonial, que es el avance de lo que se considera progreso en el imaginario social frente a la preservación de la historia. Pero, uno de los aspectos más importantes para sortear esta disyuntiva se relaciona con el aspecto económico, que está asociado, principalmente, con una concepción del patrimonio como objeto de consumo y como elemento distintivo en el marco del marketing y la competitividad urbana. Esto queda expresado en un párrafo del PER, donde el pasado y el futuro parecen convivir en "una dialéctica entre tradición e innovación, un delicado pero fecundo diálogo entre el patrimonio que Rosario no quiere resignar y el horizonte de posibilidades que aguarda ahí no más, casi a la vuelta de cualquier esquina" ( $\mathrm{Mu}-$ nicipalidad de Rosario, PER, 1998, p. 43).

Simultáneamente, es decir, a partir del PER 1998, Rosario plantea la actividad turística recreativa, cultural y de negocios como un eje fundamental a desarrollar (Municipalidad de Rosario PER, 1998), haciendo hincapié en dos cuestiones principales: la reconversión de los espacios públicos sobre el río y el incremento de los eventos culturales. Es oportuno aclarar que esta ciudad no cuenta con una tradición turística, al contrario de otras ciudades metropolitanas del interior como Córdoba, Salta y Mendoza que, por su historia y sus 
particularidades geográficas, son destinos turísticos consolidados. Surge, entonces, el interrogante sobre cómo se produce la construcción estratégica de una ciudad como nuevo destino turístico y qué rol puede desempeñar el patrimonio en ese contexto.

La posibilidad de que ciudades como Rosario ingresen en el mercado del turismo, no depende exclusivamente de la voluntad de sus gobiernos, sino que esto se produce en un contexto que fomenta cierto tipo de turismo al que estas ciudades pueden aspirar y que es el turismo de fin de semana, actividad que viene sosteniendo un crecimiento considerable en los últimos años. ${ }^{3}$ Este nuevo tipo de turismo produce en las ciudades una fragmentación determinada por los enclaves habilitados y promocionados para el turismo y aquellos espacios que son excluidos de ese mercado. Es decir, determinados espacios son investidos de nuevos sentidos con la intención de insertar a la ciudad en un mercado hasta entonces desconocido. De esta manera, las ciudades abocadas al turismo urbano diseñan circuitos y modos de circulación que se van ajustando a la optimización del tiempo recreativo en un modelo que, a partir de la compresión espacio-temporal, apuntala al fin de semana como un particular modo de turismo y como posibilidad de reactivación de las economías de ciudades intermedias, y ya no solo de grandes capitales o ciudades de tradición turística. Es en este entramado socio-cultural y económico, definido como nueva fase del capitalismo, que el patrimonio rosarino, compuesto principalmente por el río, el bagaje cultural y su arquitec- tura, surge como uno de los recursos o atractivos potenciales de explotación.

En el PER 1998 se expone la convergencia de políticas públicas orientadas a la recuperación del patrimonio natural, el río y sus islas, y la revalorización del patrimonio histórico y cultural local, como pasos inevitables que desembocan en un futuro promisorio para el desarrollo del turismo en Rosario. Es posible observar que la construcción simbólica y material de esa ciudad turística responde a un conjunto de representaciones dominantes del imaginario colectivo. En este sentido, se ponderan ciertos lugares, actores y actividades al mismo tiempo que se ocultan otro tipo de historias e identidades vinculadas con sectores populares o subalternos. Por caso, se podría mencionar la paradoja que existe en cuanto a la temática del río como patrimonio natural y cultural de la ciudad al que, sin embargo, se despoja de uno de sus actores más significativos como son los pescadores. A la hora de construir la imagen de la ciudad del río, estos trabajadores y habitantes de las orillas carecen de toda representación en la configuración de la identidad ribereña de la ciudad. Es decir, dentro de las estrategias turístico-patrimoniales solo se rescata a figuras reconocidas de la cultura, dejando de lado aquellas subjetividades o identidades que permitirían pensar en una cultura local más vinculada a los lugares y prácticas que le son propias. El río se construye y se vende como paisaje, como recurso natural para recorrer en travesías organizadas para el turismo o para visitar en verano. Sin embargo, se muestra un río sin pescadores y
3 Según la Organización Mundial de Turismo, el turismo creció el $5 \%$ en la primera mitad de 2012. Argentina no esajena a este fenómeno y en 2011 se inscribió como el principal destino turístico de América del Sur. El turismo interno creció el $362 \%$ en losúltimos diez años, ubicándose en 2011 como la tercera actividad de productos exportables generadores de divisas. El fortalecimiento de esta actividad está acompañado de numerosas politicas públicas, como la creación del Instituto Nacional de Promoción Turística en 2005, el Plan Federal Estratégico de Turismo Sustentable 2016 y el Plan Estratégico de Turismo 2020. En este marco, se ha procedido al reordenamiento de días feriados, lo cual dinamizó el turismo de fin de semana, que produjo un incremento del $47 \%$ en la cantidad de personas que viajaron los fines de semana largos frente a la misma fecha de 2011 (Instituto Nacional de Promoción Turística, INPROTUR, redcame.org. ar Cámara Argentina de Turismo, informe 2011).

territarias 33

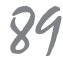


sin isleños. Rosario pasó de ser una ciudad de espaldas al río, idea que se empleó como argumento para los primeros procesos de reconversión costera desde la década del noventa, a ser una ciudad contemplativa del río o enfocada únicamente en sus usos recreativos.

Además, lentamente, la ciudad fue adquiriendo centralidad como plaza para la realización de eventos culturales, deportivos, científicos y de negocios. "Frente a esta nueva situación, y gracias al esfuerzo coordinado del sector público y el privado, la ciudad viene desarrollando acciones y políticas orientadas a definir un perfil turístico y potenciar su atractivo" (Municipalidad de Rosario, PER, 1998, p. 207). También se observa que el tema del patrimonio emerge vinculado al análisis contextual de la nueva economía, signada por la flexibilidad, los servicios y el consumo creciente de bienes tangibles y, sobre todo, intangibles. En este marco, si bien el patrimonio es presentado con los objetivos de preservación y rehabilitación, también se lo rescata como un recurso para dinamizar la economía local. Lo mismo ocurre con la actividad turística, presentada como nuevo motor de la economía local y como un "eje conciliador entre el crecimiento económico, la preservación del patrimonio cultural e histórico y las actividades de recreación y placer" (Municipalidad de Rosario, PER, 1998, p. 207). La estrategia turístico-patrimonial desarrollada se sustenta en uno de los proyectos denominado Preservación del patrimonio urbano y arquitectónico, como insumo destacado para el desarrollo local de la cul- tura, las industrias culturales y el turismo, afirmando que:

[...] en las sociedades contemporáneas, el desarrollo cultural constituye, no solamente un elemento de identidad territorial y mejoramiento de la calidad de vida, sino también un factor importante para el posicionamiento nacional e internacional y un componente significativo de la imagen de la ciudad ( $\mathrm{Mu}-$ nicipalidad de Rosario, PER, 1998, p. 98).

El turismo cultural es una actividad que encierra significaciones particulares. Autores como Lash y Urry (1998) afirman que el modelo de ciudad cultural se orienta a atraer capitales sociales, económicos y simbólicos para promover la producción a partir de las ideas. $\mathrm{Al}$ respecto, en Rosario las políticas culturales de espectáculos se fueron complementando con políticas de patrimonio desde las cuales se busca rescatar y señalizar edificios y circuitos arquitectónicos factibles de ser explotados turísticamente. Por eso, se presenta a Rosario como cuna de talentos, semillero de actores, artistas y humoristas, lo que busca construir una imagen de una ciudad culta, talentosa y creativa que encauce el proceso de estetización del lugar (Lipovetsky \& Serroy, 2013). A esto se suma la difusión de los llamados circuitos de diseño y circuitos gastronómicos. Turismo y cultura, dos actividades propias de la nueva fase del capitalismo, se unen como factores de desarrollo y progreso que se retroalimentan. El patrimonio urbano y arquitectónico es considerado como parte de la identidad 
urbana y, por ende, capital cultural de la ciudad en los discursos oficiales (Municipalidad de Rosario, PUR, 2007).

Existe una creciente culturalización de las prácticas turísticas en las que Cassián Yde (2012) detecta un desplazamiento de la ciudad cultural a la ciudad creativa donde al arte, ocio y cultura se suma el valor de la innovación y la creatividad que se traducen en ciudades de "espíritu dinámico, flexible, abierto y bohemio [que] [...] producen un valor altamente capitalizable" (Cassián Yde, 2012, p. 178). Esto se puede ver con claridad en el Plan Estratégico Rosario Metropolitana (PERM) lanzado en 2010. Allí se afirma que Rosario se consolidó como punto de atracción de eventos nacionales e internacionales gracias a que "su oferta cultural destacada y su patrimonio histórico y arquitectónico, le aportan a Rosario los factores diferenciales que le permiten fortalecer su proyección a escala nacional e internacional" (Municipalidad de Rosario, PERM, 2010a, p. 52). En este Plan también se expone la necesidad de poner en valor el patrimonio histórico-arquitectónico de la región para potenciar las actividades culturales, de negocios, de recreación y, por ende, de turismo urbano.

En esta primera exploración realizada, se puede observar el rol destacado que posee el patrimonio arquitectónico como recurso de atracción turística. El impulso de políticas orientadas a la preservación y rehabilitación está acompañado por la idea de la identidad cultural local como valuarte a ser reconstruido a partir del capital patrimonial. De todos modos, parece estar más relacionado con el consumo turístico que a una preocupación por el fortalecimiento de la identidad local.

\section{Marketing urbano y espacialización de las estrategias turístico-patrimoniales}

En paralelo al planteo de desarrollar la industria turística, surge la necesidad de desarrollar una imagen o marca de ciudad capaz de atraer inversores, visitantes y contener al propio habitante en esta nueva etapa. Como se mencionó, el marketing urbano se orienta hacia dos grandes públicos objetivo, uno interno, el habitante de la propia ciudad, y otro externo, el habitante de otras ciudades, potencial turista. La competencia en la que se ven inmersas las ciudades turísticas plantea una serie de paradojas que tienen consecuencias sobre la vida urbana. Por un lado, se le exige a la ciudad productos nuevos, innovadores, exclusivos y, por el otro, espacios patrimoniales que sean propios y que permitan distinguirla. Al mismo tiempo, se debe contener la extrañeza del visitante propiciándole lugares comunes donde su propia experiencia como turista pueda fundirse con la del habitante.

En la etapa orientada por el PER, el énfasis estaba puesto en explotar los recursos naturales y culturales como atractivos turísticos. En relación con los recursos naturales, las intenciones se orientaban a consolidar los espacios públicos con fines recreativos y turísticos, destinados tanto a los propios habitantes como al turista. Esta directriz se materializa en el slogan territarias 33

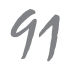




\section{territarias 33}

92
"Rosario, la mejor ciudad para vivir" más orientada al público interno que al potencial visitante. Esto se vincula con un contexto de imagen negativa de la ciudad que emplazaba sus estrategias, no solo a atraer inversores sino también a contener a sus residentes. Posteriormente, en 2010 se presenta el Plan de Desarrollo de Turismo Sustentable 2010-2018 (PDTS), a partir del cual se observa un desplazamiento en la nueva marca ciudad: "Yo amo Rosario", ahora, direccionada hacia el turista. Este slogan, inspirado en la imagen de ciudad turística global como Nueva York, Barcelona y París, pone de manifiesto las aspiraciones de la ciudad. El empleo de esta imagen permite corroborar la idea expuesta por Harvey (2008), quien sostiene que en este capitalismo, donde prima la producción de imágenes, también se genera un proceso de réplicas seriadas de estas. De este modo, analizando el empleo de este logo en todas las ciudades que aspiran a consolidar una imagen de ciudad internacional, se puede afirmar que las identidades locales quedan cooptadas por imágenes globales que tienen un sentido propio más allá del referente urbano que las adopte. El "Yo $\bullet "$ refiere a una ciudad preparada para el ciudadano del mundo, una ciudad amigable, desarrollada, es una marca que funciona como sello de calidad del imaginario urbano dominante (Vera, 2013).

Teniendo en cuenta que la identidad urbana se representa a partir de múltiples aristas, es importante que la marca ciudad esté acompañada por nuevos productos que permitan satisfacer las demandas de los turistas. En este punto se destaca el caso del patrimonio, ya que resulta un atractivo turístico capaz de generar productos-íconos que motiven la visita. El caso de Rosario permite analizar el proceso de construcción de una imagen, marca y modelo urbano con fuerte anclaje en lo cultural, siendo sus artistas y producciones, como así también las obras arquitectónicas, los principales referentes de las representaciones urbanas oficiales, es decir, los objetos donde se encarna o in-corpora el imaginario urbano, en términos de Silva (2006). La perspectiva del patrimonio como patrimonio cultural es la noción predominante en los planes analizados. Esto se encuentra también alineado con el auge que ha tomado el concepto de turismo cultural descrito. Como se mencionó, el tipo de turismo que recibe Rosario se concentra en los fines de semana. El corto tiempo que el visitante está en la ciudad se optimiza ofreciéndole circuitos puntuales vinculados al patrimonio tangible e intangible. La organización significativa del espacio "determina una relación con el pasado que se supone común" (Delgado, 2010, p. 92) y que, a su vez, se puede relacionar con el capital emotivo, como se puede observar con la explotación de la imagen del Che Guevara o Lionel Messi como personalidades locales. Es posible pensar que esta organización significativa del espacio, a partir del patrimonio, es delineada por el poder local y por ello está en consonancia con la diagramación planificada de la imagen que se pretende construir de la ciudad, tanto desde el gobierno local como de las elites empresariales interesadas 
en el proyecto modélico. ${ }^{4}$ En este marco, el Plan de Desarrollo de Turismo Sustentable tiene como objetivo detectar nuevos productos, ampliar la oferta de servicios y desarrollar:

[...] circuitos innovadores que muestren el patrimonio histórico y cultural desde una perspectiva sustentable, $[\ldots]$, relevando $\mathrm{y}$ poniendo en valor atractivos tangibles e intangibles y segmentando la oferta según el interés de los visitantes que arriben a nuestra ciudad [...]. Apoyándose en procesos de calidad y marketing (Municipalidad de Rosario, PDTs, 2010b, 32).

Dentro del programa Desarrollar y Potenciar Productos del PDTS se presenta el Proyecto Valoración del Patrimonio que busca registrar recursos de distinto tipo para confeccionar productos turísticos. En este sentido, se puede desglosar la estrategia turístico-patrimonial en dos grandes ejes: uno tangible, vinculado al patrimonio urbano arquitectónico y otro intangible, definido por los aspectos culturales.

\subsection{Nuevas centralidades urbanas: los circuitos turístico-patrimoniales ${ }^{5}$}

En relación con el patrimonio tangible, vehiculizado en la puesta en valor del patrimonio urbano arquitectónico mediante la preservación y rehabilitación edilicia, se puede apreciar la organización de diversos circuitos turístico-patrimoniales que contienen este proceso. Esto se vincula, como ya se mencionó, con las necesidades espacio-temporales contemporáneas, donde las ciudades abocadas al turismo urbano diseñan circuitos y modos de circulación que se van ajustando a la optimización del tiempo recreativo en un modelo que, en Rosario, apuntala al fin de semana como un particular modo de turismo y como posibilidad de reactivación de las economías de ciudades intermedias o ciudades sin tradición turística.

Los circuitos promocionados oficialmente para el turismo, ${ }^{6}$ que se presentarán a continuación, se ubican, casi exclusivamente, en la zona central de la ciudad (delimitada por el río, el Bulevar Oroño y Avenida Pellegrini) potenciando en esta zona las intervenciones culturales y patrimoniales impulsadas desde el gobierno local, ya sea mediante normativas, acciones o convenios público-privados. Estos están condensados en la figura 1.

En primer lugar, se encuentra el Núcleo Fundacional (ref. 1 de la figura 1) que comprende el casco histórico y las construcciones que se ubican alrededor de la plaza central (25 de mayo) el Palacio del Correo, el Palacio de los Leones, el Museo de Arte Decorativo, el Consulado de España, la Catedral y el edificio Bola de Nieve. En este punto, hay que tener en cuenta que Rosario fue declarada ciudad recién en 1852, año en el que se abre su puerto al comercio internacional y se inicia un periodo de crecimiento. Esto significa que su casco histórico no reviste de la antigüedad que poseen los núcleos fundacionales de otras ciudades argentinas como Buenos Aires o Córdoba, por mencionar algunas.
${ }^{4}$ Una expresión de estas asociaciones público-privadas es la Fundación Ciudad de Rosario que tiene como objetivo: "Posicionar a Rosario a nivel local, nacionale internacional como ciudad con espiritu metropolitano, que resulte atractiva para personas, empresase instituciones que quieran instalarse, visitar o hacer negocios en nuestra región y se constituya en fuente de orgullo para quienes habitamos en ella". $\Upsilon$ "desarrollar el modelo Rosario, definiendo el posicionamiento estratégico que deseamos lograr, agregando valor a todo lo local, para luego garantizar su promoción y difusión”. Entre los miembros se encuentran destacadas empresas locales y la Municipalidad de Rosario (bttp://www. fundacionrosario.org.ar/).

${ }^{5}$ Un primer avance de este tópico se presentó en coautoría con Roldán, y Pascual, como ponencia: "De la residencia al turismo. Imaginarios y discursos sobre el espacio público de Rosario". Bienal del coloquio de transformaciones territoriales AUGM, Córdoba, noviembre, 2014.

${ }^{6}$ www.rosario.gov.ar, www. rosarioturismo.com

territarias 33

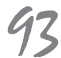




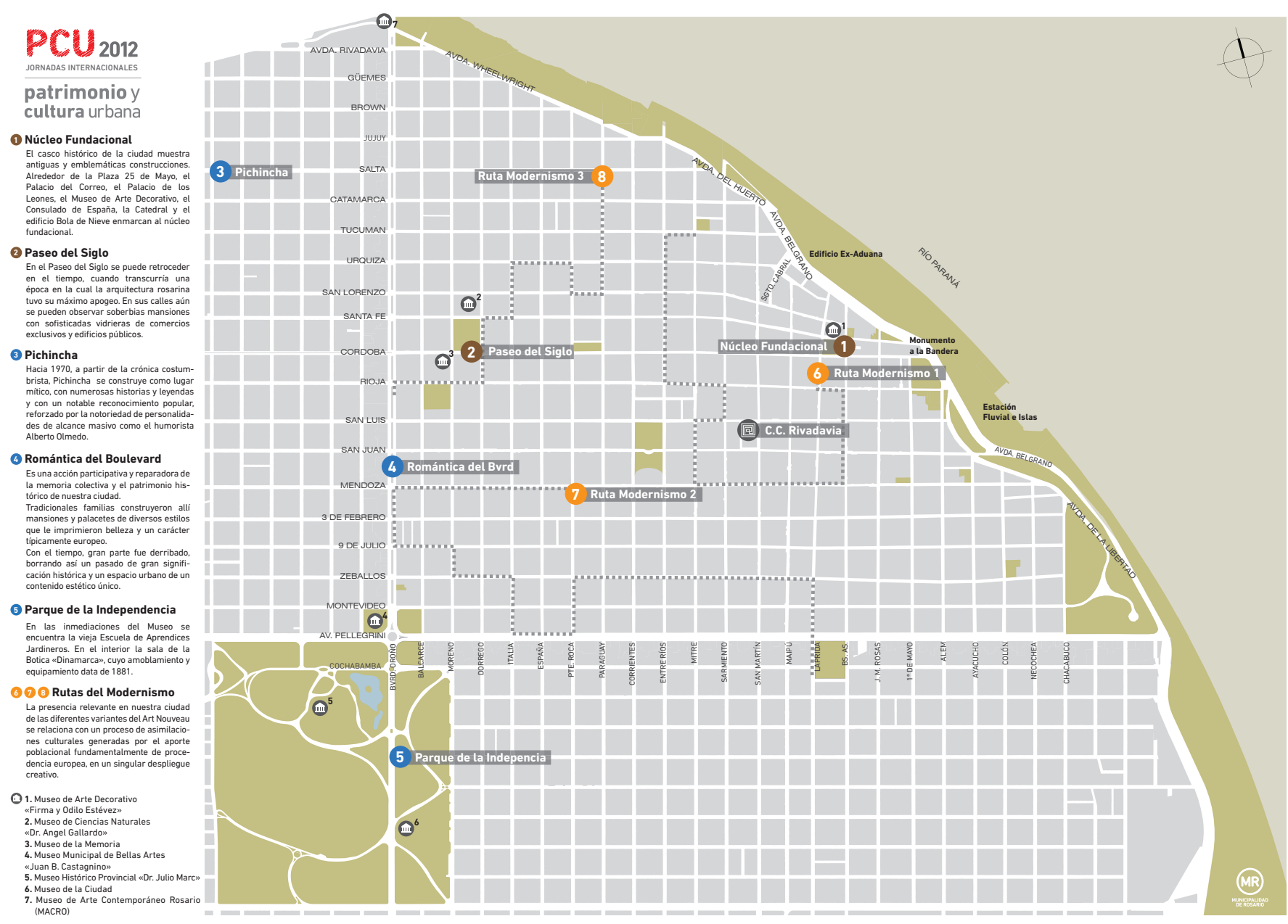

Fuente: Municipalidad de Rosario (2012). Disponible en www.rosario.gov.ar/sitio/verArchivo?id=7688\&tipo=objetoMultimedia territorios $33 \quad \begin{aligned} & \text { cuadras de la calle Córdoba, desde la altura } \\ & 1500 \text { y hasta la 1800. Allíse localizan algu- }\end{aligned}$ 94
Por ejemplo, el Palacio de los Leones, sede de la Municipalidad, se construyó en 1886.

Luego, se presenta el Paseo del Siglo (ref. 2 de la figura 1), que incluye algunas nas casonas de principios de siglo Xx, 1920 aproximadamente, periodo definido como el "apogeo arquitectónico" de la ciudad.

A continuación, se encuentra el circuito Rutas del Modernismo (ref. 6, 7, 8 de la figura 1), que es un recorrido por algunas 
Figura 2. Rutas del Modernismo

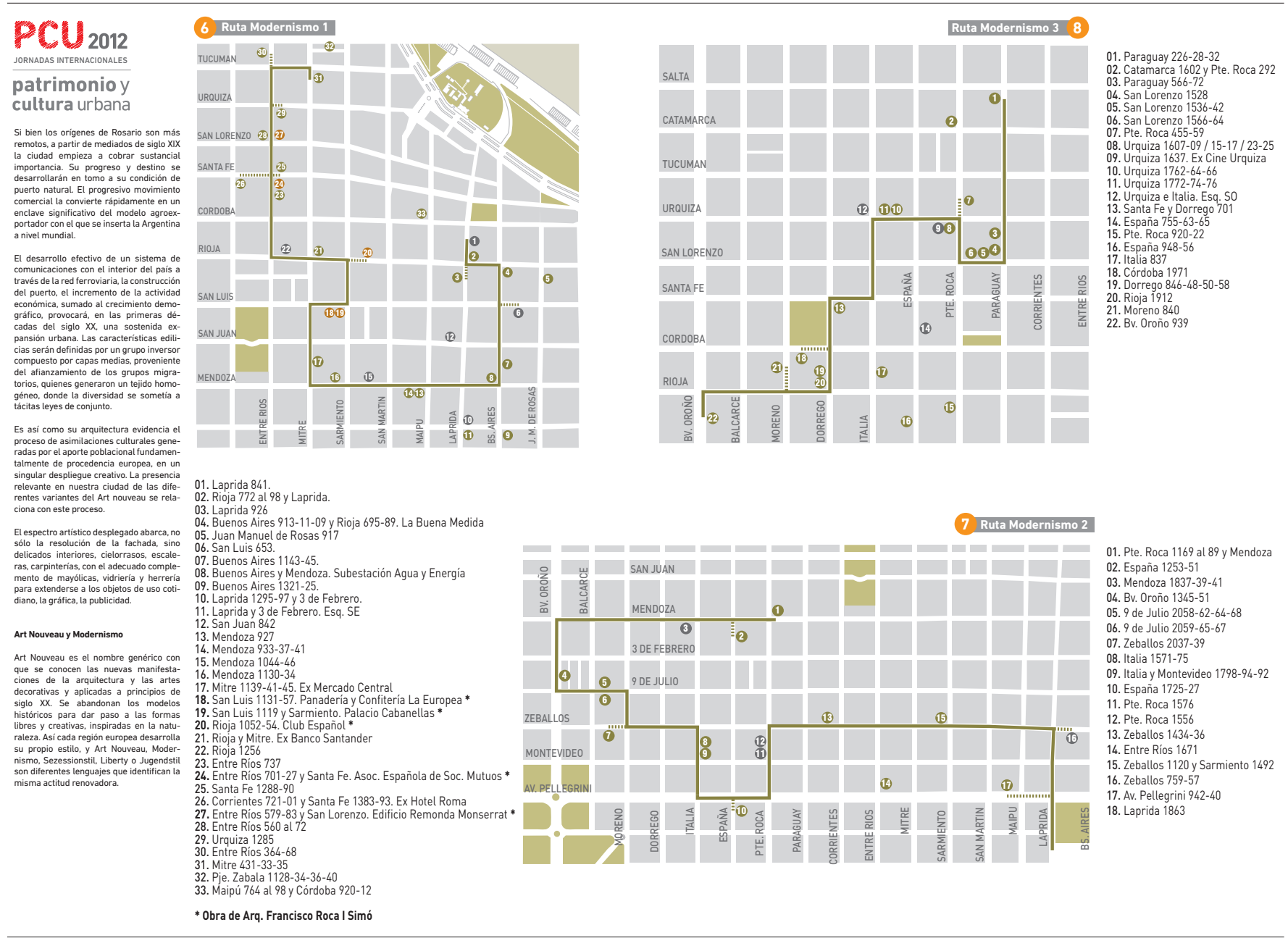

Fuente: Municipalidad de Rosario (2012). Disponible en www.rosario.gov.ar/sitio/verArchivo?id=7689\&tipo=objetoMultimedia

fachadas que tienen la impronta del Art Nouveau. Si bien, muchas de estas casas son propiedad privada, están dentro del catálogo patrimonial municipal. La mayoría de ellas se ubica en la zona céntrica (figura 2).

ESTRATEGIAS PATRIMONIALES Y TURÍSTICAS: SU INCIDENCIA EN LA CONFIGURACIÓN URBANA
Por último, se presenta el circuito Romántica del Boulevard (ref. 4 de la figura 1), que es una reconstrucción fotográfica de las mansiones y palacetes construidas en Bv. Oroño a principios de siglo $\mathrm{xx}$, de diversos estilos y demolidos para realizar edificios territarias 33 95 
${ }^{7}$ www.rosario.gov.ar/sitio/ arquitectura/bv_oronio2.jsp

territarios 33 96 modernos, fundamentalmente en las décadas de los sesenta y setenta. Esta intervención busca recrear el pasado del bulevar mediante fotografías de las antiguas construcciones en marcos de 40 x $60 \mathrm{~cm}$, ubicadas en frente de las "nuevas" (figura 3 ).

El objetivo de este circuito es crear una galería de la memoria ${ }^{7}$ que una los museos de arte Castagnino - Bv. Oroño y Av. Pellegrini- y Macro - Bv. Oroño y el río-. En relación con esto, también se recuperaron ciertos lugares con impronta turística como los Silos Davis, donde se ubica el museo de arte contemporáneo Macro (figura 4).

Figura 3. Romántica del Bulevar

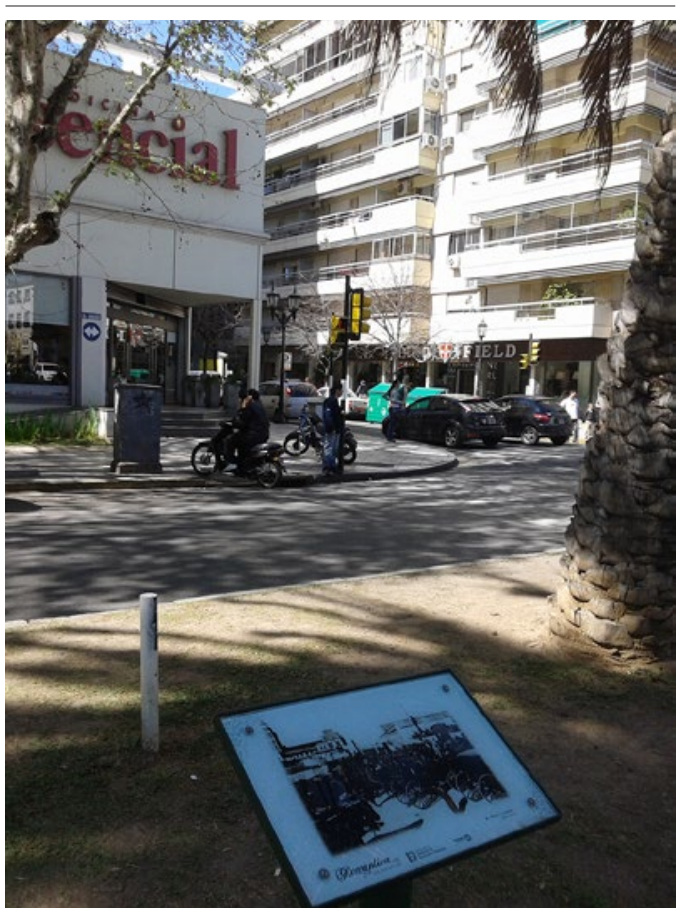

Fuente: elaboración propia (septiembre, 2014).
El paseo Romántica del Bulevar resulta paradigmático en relación con los otros circuitos patrimoniales porque es una intervención exclusivamente representacionalista de la ausencia. Ausencia de los objetos que connotan un pasado pretendidamente esplendoroso y moderno, ausencia de políticas de conservación patrimonial, ausencia de memoria colectiva sobre determinado valor depositado en lo arquitectónico. Se podría hablar, entonces, de una ausencia expresiva como complemento del fenómeno que Bohigas (1978) define como presencia expresiva al referirse a aquellos objetos que no tienen ninguna funcionali-

\section{Figura 4. Silos Davis - Museo MACRO}

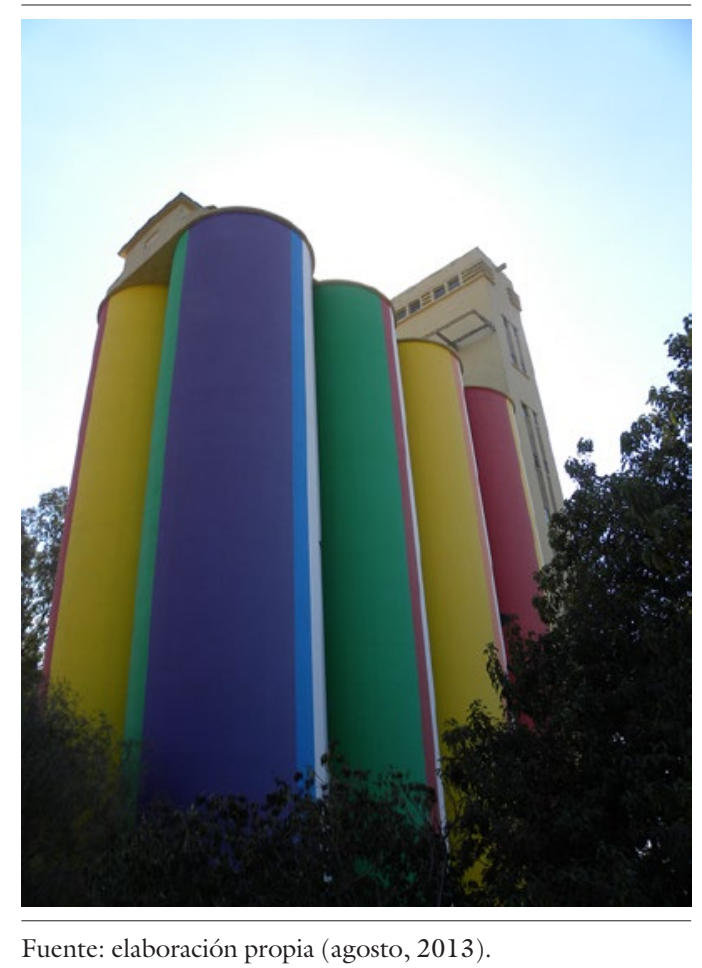


dad en la ciudad, pero que poseen un valor psicológico y simbólico integrado a la imagen de esa ciudad. También se podría interpretar este circuito como un cementerio de lo patrimonial, una muestra de fotos de lo que ya no está, de lo que en realidad pudo ser patrimonial pero ya no existe. Es justamente la ausencia lo que dota de sentido y significación patrimonial a este recorrido.

Respecto del patrimonio cultural intangible, en el PDTS se destaca que el turismo cultural es un instrumento de dinamización económica y reestructuración urbana local. Este consta, principalmente, de la búsqueda de nuevas experiencias de vida y conocimiento, además de incurrir en la tradicional visita de sitios históricos y monumentos. Según un sondeo realizado a modo de diagnóstico en la confección del Plan, las características culturales valoradas por quienes la visitan son "sus bellas mujeres, el fútbol, la música, las religiones que se practican, su diversidad arquitectónica y su variada gastronomía, que entre otras conforman su patrimonio cultural" (Municipalidad de Rosario, PDTs, 2010b, p. 37).

Por otra parte, tanto en el PDTs como en el PER y el PERM, es constante la apelación a las personalidades de la ciudad como símbolos de identidad urbana y patrimonio cultural. Desde los cantantes de la trova rosarina, los humoristas Olmedo ${ }^{8}$ y Fontanarrosa, ${ }^{9}$ deportistas como Messi ${ }^{10}$ —actual cara de la marca ciudad-_ el histórico revolucionario Ernesto 'Che' Guevara y artistas como Berni, Gambartes y Grela reconfiguran ciertos espacios urbanos.
En este aspecto, se hará énfasis en dos circuitos que ponen de manifiesto las afirmaciones realizadas respecto de las relaciones entre marca ciudad, patrimonio, turismo y configuración urbana. En primer lugar, el recorrido La ruta del Che en Rosario (figura 5) donde se señalizan sitios públicos donde existen murales, un centro de estudios y monumento al Che, el lugar de nacimiento y el Parque Independencia que se encuentra intervenido por grandes fotografías que señalan la presencia del Che de bebé con sus padres, y una antes de emprender su viaje por Latinoamérica. Este recorrido connota el proceso de construcción de la imagen de Rosario, ligado a la figura de un personaje que, en lo concreto, no tuvo una vida muy vinculada a la ciudad, más allá de su nacimiento y algunas visitas. Se puede considerar esta estrategia como una elaboración que, si bien no falsea la historia - lo que en el ámbito del patrimonio se denomina falso histórico-, al menos la fuerza al erigir un relato caprichoso sobre una identidad urbana que se muestra fuertemente influenciada por los valores y la relevancia histórica que encarna Ernesto 'Che' Guevara.

En segundo lugar, la intervención denominada Museo Urbano Arte a la Vista (figura 6), donde una vez más se comprueba la centralización de los circuitos turístico-patrimoniales. En esta acción se propone al espacio público urbano como marco que reconstruye y muestra la memoria pictórica local, con un museo a la vista de todos $^{11}$ a partir de la recreación en murales de obras de artistas reconocidos
${ }^{8}$ En homenaje a esta personalidad local, en 2007, se instaló una estatua de bronce tamaño real en el paseo de los artesanos del barrio Pichincha, donde nació y vivóhasta su juventud (La Capital, 27/4/2007).

${ }^{9}$ A este artista se lo reconoció construyendo un espacio de homenaje en el Parque a la Bandera en la costa central donde se colocaron estatuas gigantes de sus personajes más conocidos: Boggie, Inodoro Pereyra y Eulogia (La Capital, 24/12/2014).

${ }^{10}$ En el marco del proyecto de reconversión urbanistica del ex Batallón de Comunicaciones 121, en el sur de la ciudad, se proyecta la creación de un Museo del Deporte con un pabellón especial destinado a Messi, orientado también a movilizar el turismo alrededor de la imagen de este deportista de prestigio internacional.

${ }^{11}$ www.rosario.gov.ar/sitio/ lugaresVisual/verLugar. do? id $=3120$

territarias 33

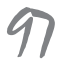


Figura 5. La ruta del Che en Rosario

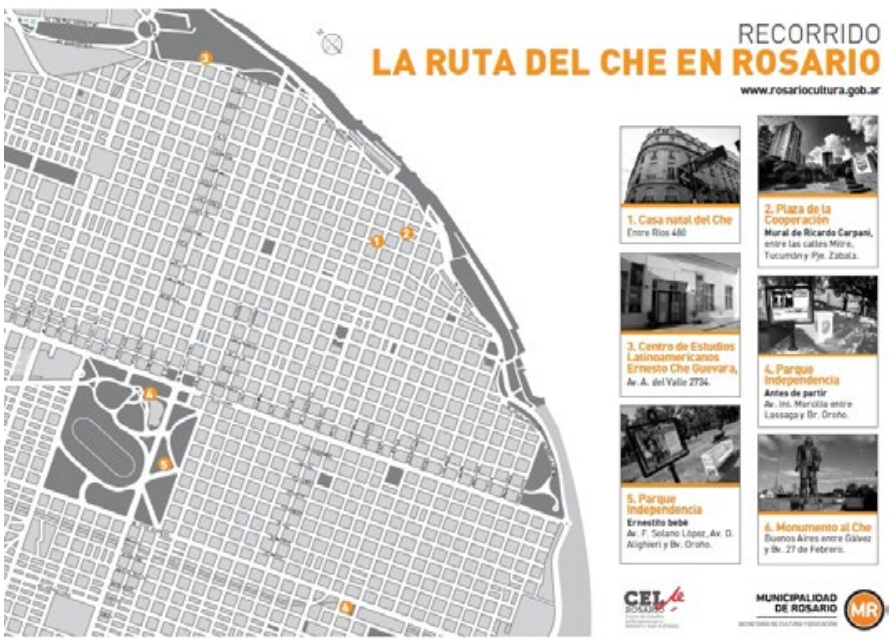

Fuente: Municipalidad de Rosario (s/f). Disponible en www.rosariocultura.gob.ar/galerias/ archivos/los\%20caminos\%20del\%20che.pdf

Figura 6. Museo Urbano Arte a la Vista

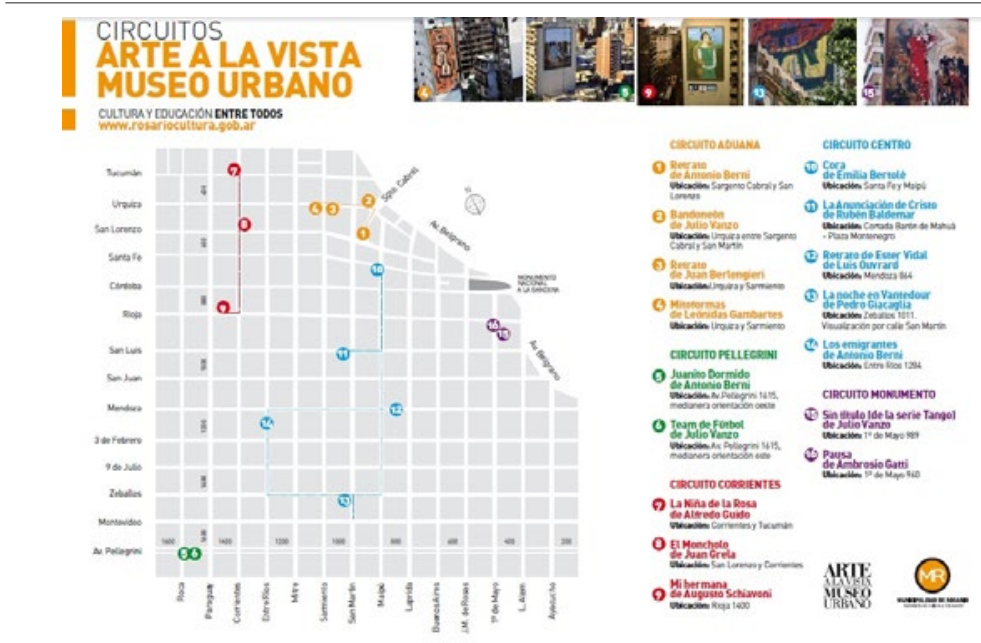

Fuente: Municipalidad de Rosario (s/f). Disponible en www.rosariocultura.gob.ar/galerias/ archivos/recorridos-autoguiados-museo-urbano-arte-a-la-vista/Mapa\%20Museo\%20 Urbano\%20Arte $\% 20 \mathrm{a} \% 201 \mathrm{l} \% 20$ Vista.pdf

\section{territarias 33}

en las medianeras de edificios. Esta acción se desarrolla a partir de convenios con empresas privadas que funcionan como patrocinadores de la iniciativa. Entre los artistas que se recrean, se encuentra a Antonio Berni, Leónidas Gambartes, Julio Vanzo y Juan Grela, quienes figuran en los planes mencionados como personalidades distinguidas de la cultura rosarina de potencial patrimonial y turístico.

En este punto, es importante relacionar las intervenciones Romántica del $\mathrm{Bu}-$ levar y Museo Urbano Arte a la Vista, ya que permite retomar el análisis que realiza García Canclini (2010), quien plantea que lo que se considera arte y patrimonio está estrechamente vinculado a los sectores dominantes que controlan y tienen el poder interpretativo sobre la cultura. Asimismo, estos itinerarios ponen de relieve las imbricaciones entre arte, cultura y patrimonio, al evidenciar la intencionalidad oficial de construir imágenes de la sociedad urbana rosarina y al exponer como valores homogéneos y compartidos ciertos bienes y espacios culturales acordes con la estrategia de desarrollo de turismo urbano puesta en marcha. A su vez, condensa símbolos y espacios, actuando como metáfora del deseo de ciudad, exhibiendo materialmente rasgos muy sobresalientes del imaginario urbano dominante que reúne lo antiguo, lo arquitectónico patrimonial, lo artístico y lo contemporáneo como factores inherentes a la identidad local.

Por último, se aprecia también un caso de recualificación urbana que remite al proceso barcelonés analizado por Delgado

Paula Vera 
(2010) sobre la refuncionalización y monumentalización de chimeneas industriales. En Rosario, se manifiesta en el sector ferroportuario donde, a lo largo de la ribera, es posible ver un sector intervenido, recualificado, que expone la ciudad portuaria, industrial y dinámica del pasado y el pasaje a una nueva ciudad, también dinámica pero ahora adaptada a la economía de la cultura y la innovación. Este sector, denominado Ciudad Joven (figura 7), compone una imagen urbana que ofrece a esta ciudad para el turismo que puede consumir algo de ese pasado, junto a los productos culturales de un presente que busca construirse como cultural y vanguardista.

En los últimos años se fue construyendo una escenografía urbana de la nueva ciudad, donde conviven amigablemente el patrimonio, la cultura, la innovación, las torres de alta gama, los recorridos gastronómicos y la centralidad ofrecida al turismo y a las clases medias como las nuevas postales rosarinas. Para ello, se relata un pasado que justifica y da fuerza a los sueños a futuro en que se enmarca el Modelo Rosario, una imaginación urbana dominante legitimada por el gobierno local, el empresariado y sectores académicos

\section{Conclusiones}

Luego del recorrido realizado en este trabajo, se puede afirmar que los aspectos patrimoniales ocupan un lugar central en las estrategias de turismo urbano, al mismo tiempo que este incide, junto al modelo o marca ciudad, en la construcción y

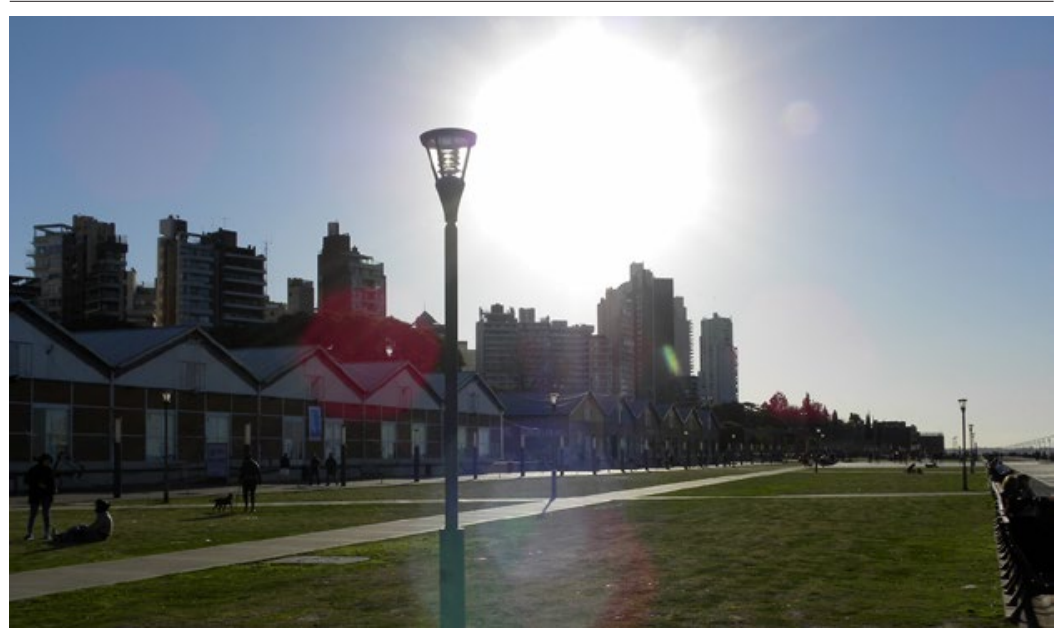

Fuente: elaboración propia (agosto, 2014).

legitimación de cierto pasado. En el caso analizado cabe preguntarse, ¿qué imagen de Rosario buscan construir los circuitos patrimoniales?, ¿qué pasado quieren relatar? Claramente, se busca revivir un pasado de progreso, modernidad, vanguardia, arte $\mathrm{y}$ cultura que, desde principios del siglo $\mathrm{Xx}$, está instalado en las representaciones hegemónicas de los discursos oficiales, periodísticos e historiográficos locales. ${ }^{12}$ Sobre estas mismas significaciones se enfatiza en el presente, a partir de las estrategias de marketing urbano, impulsadas para potenciar la ciudad hacia un futuro de innovación, progreso y, por ende, de éxito. Esto se vincula con los procesos de activación de repertorio patrimonial (Prats, 1998) y un imaginario patrimonialista (Hiernaux, 2006) en donde se comprueba que existe una estrategia política, es decir, se trata de la espacialización
${ }^{12}$ Este tema se trabajó en profundidad en la tesis doctoral inédita "Imaginarios urbanos y tecnológicos en los procesos de construcción material y simbólica de la ciudad moderna y contemporánea. El caso de la ciudad de Rosario en el contexto de las metrópolis del interior de Argentina”. Sobre la relación entre progreso $y$ espacialidades urbanas en Rosario se puede consultar Vera (2014).

territarias 33

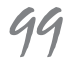


y señalización de un pasado políticamente correcto a los intereses contemporáneos.

Desde fines de la década del noventa emergieron, en los discursos oficiales, las problemáticas del patrimonio y el turismo urbano como potenciales recursos de dinamización económica y en esta dirección se sigue construyendo a la ciudad como una unidad de negocios en donde el patrimonio tangible e intangible tiene una función bastante definida y orientada al consumo cultural, convirtiéndose en una clave estratégica para el desarrollo de Rosario como una nueva ciudad turística.

La vinculación patrimonio-turismo también pone de manifiesto la implicancia del sector privado en la construcción del modelo Rosario. Una imagen urbana imaginaria que cuenta con una fuerte impronta simbólica y material viabilizada en numerosas oportunidades por el patrocinio de empresas locales o concesiones a privados que decantan en una progresiva privatización del espacio público en pos del turismo y el consumo que las clases medias y altas pueden hacer de la ciudad. Por otra parte, las políticas vinculadas a los convenios público-privados permiten constatar una idea planteada por Hiernaux (2006), quien afirma que en muchos casos los gobiernos de supuesta orientación de izquierda terminan interviniendo en las reformas del espacio público en favor de intereses privados bien concretos. Quizá, el caso más contundente sea el de las concesiones de los espacios públicos sobre la ribera para emprendimientos gastronómicos.
Respecto de las posibles tensiones que se pueden suscitar sobre el turismo y el patrimonio, hay que destacar que la protección patrimonial tiene aceptación general porque consolida, a su vez, la representación dominante del imaginario urbano que considera a Rosario como una ciudad del progreso, con importantes construcciones arquitectónicas, lo que refuerza también los símbolos identitarios locales y el sentido de pertenencia. Lo mismo ocurre respecto del patrimonio intangible y la idea, fuertemente arraigada, de Rosario como ciudad de la cultura. En el área central, depositaria de las intervenciones y reconversiones urbanísticas, tanto patrimoniales como turísticas, se genera un proceso de embellecimiento del espacio público que utilizan tanto los visitantes como los habitantes en su vida cotidiana. Por otro lado, la puesta en escena de símbolos que refuerzan la identidad urbana promueve cierto sentido de pertenencia y orgullo local que atenúa las disidencias y opera con un efecto de disminución de posibles conflictos. De hecho, en los procesos analizados no se registran manifestaciones de resistencia organizadas que pongan en cuestión las acciones del poder local.

En relación con los procesos de reconfiguración urbana, ligada a las estrategias turístico-patrimoniales, se destacan la creación de circuitos, la escenificación de ciertos fragmentos urbanos, la estetización, elitización y privatización paulatina de espacios públicos en pos de generar postales turísticas y la consolidación del área central como espacio valioso para ser visitado, tran-

\section{territarias 33} 100 
sitado y consumido porque es allí donde se concentran las actividades culturales, los espacios de ocio, las intervenciones públicas y los recorridos turístico-patrimoniales.

Por último, en relación con la hipótesis planteada al comienzo de este artículo, se puede afirmar que, en el caso de Rosario, las acciones, imágenes y materializaciones que implican a las políticas de turismo y de conservación o rehabilitación patrimonial están en concordancia con la marca ciudad que se construye desde el gobierno local, lo que genera una sinergia entre el modelo urbano, el consumo turístico y el reservorio patrimonial. En definitiva, se busca en el patrimonio una clave simbólica identitaria que dé cuenta del pasado y ofrezca posibilidades de consumo cultural, histórico y arquitectónico por parte de los visitantes y también del propio habitante de la ciudad.

\section{Referencias}

Benko, G. (2000). Estrategias de comunicación y marketing urbano. Eure, 26(79), 67-76.

Berger, P., \& Luckmann, T. (2008). La construcción social de la realidad. Buenos Aires: Amorrortu.

Bohigas, O. (1978). Proceso y erótica del diseño. Barcelona: La Gaya Ciencia.

Calle, V. M., \& García, H. M. (1998). Ciudades históricas: patrimonio cultural y recurso turístico. Revista Ería, 47, 249-266.

Cassián, Y. N. (2012). De qué está hecha una ciudad creativa. Una propuesta para abordar la cultura, el ocio y la creativi- dad en la urbe contemporánea. Atenea Digital, 12(1), 169-190.

Castells, M. (1997). La era de la Información. Economía, sociedad y cultura. Madrid: Alianza Editorial.

Castoriadis, C. (2003). La institución imaginaria de la sociedad. Buenos Aires: Tusquets.

Delgado, M. (2010). La ciudad mentirosa. Fraude y miseria del Modelo Barcelona. Madrid: Catarata.

Dwyer, L., \& Kim, C. (2003). Destination Competitiveness: Determinants and Indicators. Current Issues is Tourism, 6(5), 369-414.

Fundación Banco Municipal de Rosario (2012). Construcción en Rosario 20002011. El boom y los nuevos escenarios. Disponible en: http://www.fundacionbmr. org.ar/files/etiquetas_descripciones_ adjuntos/la_construccion_en_rosario_ el_boom_y_los_nuevos_escenarios_01. pdf

Fundación Banco Municipal de Rosario (2012). Informe especial. Construcción en Rosario 2000-2011. El boom y los nuevos escenarios. Disponible en www.fundacionbmr.org.ar

García Canclini, N. (2007). Imaginarios urbanos. Buenos Aires: Eudeba

García Canclini, N. (2010). La sociedad sin relato. Antropología y estética de la inminencia. Buenos Aires: Katz.

Harvey, D. (1990). La condición de la posmodernidad: Investigación sobre los origenes del cambio cultural. Buenos Aires: Amorrortu editores. territarias 33

101 
Harvey, D. (2008). La libertad de la ciudad. Revista Antipoda, 7, 15-29.

Hiernaux, D. (2006). Los centros históricos: jespacios posmodernos? (De choques de imaginarios y otros conflictos). En A. Lindón, D. Hiernaux, \& M. A. Aguiar (coords.), Lugares e imaginarios en la metrópolis, (pp. 27-41). Barcelona: Anthropos.

Judd, D. (2003). El turismo urbano y la geografía de la ciudad. Revista Eure, XXIX(87), 51-62.

Lash, S., \& Urry, J. (1998). Economías de signos y espacio. Sobre el capitalismo de la posorganización. Buenos Aires: Amorrortu.

Lipovetsky, G., \& Serroy, J. (2013). L'esthétisation du monde. París: Éditions Gallimard.

Lury, C. (2007). Haciendo y viviendo el negocio de Barcelona: Espacio, valor y poder de la marca. En YProductios (Ed.), Producta50 (pp.118-133). Barcelona: CASM.

MacCannell, D. (2007). Lugares de encuentros vacios. Barcelona: Editorial Melusina.

Municipalidad de Rosario (1998). Plan Estratégico Rosario PER.

Municipalidad de Rosario (2010a). Plan Estratégico Rosario Metropolitano +10 PERM.

Municipalidad de Rosario (2010b). Plan de Desarrollo de Turismo Sustentable 20102018 PDTS.
Municipalidad de Rosario (2011). Plan Urbano Rosario 2007-2017 PUR.

Pesavento, S. (1995). Muito além do espaço: por uma história cultural do urbano. Estudios Históricos, 8(16), 279-290.

Prats, L. (1998). El concepto de patrimonio cultural. Política y Sociedad, 27, 63-76.

Ritchie, J. R. B., \& Crouch, G. I. (2003). The competitive destination. Wallingford: CAB International Publishing.

Silva, A. (2006). Imaginarios urbanos. Colombia: Arango Editores.

Theodore, N., Peck, J., \& Brenner, N. (2009). Urbanismo neoliberal: la ciudad y el imperio de los mercados. Revista Temas Sociales, 66, 1-11.

Vera, P. (2013). Imaginarios urbanos y procesos de urbanización en las nuevas ciudades turísticas. El caso de Rosario, Argentina. Revista Bitácora Urbano Territorial, 22(1), 153-162. Disponible en www.revistas.unal.edu.co/ index.php/bitacora/article/viewFile $/ 34607 /$ pdf_477

Vera, P. (2014). El progreso como ensoñación social. Espacialidades de la Modernidad en Rosario, Argentina. Anuario Revista Digital de la Escuela de Historia, 25, 57-90. Disponible en http://web. rosario-conicet.gov.ar/ojs/index.php/ Anuario/article/view/302/349 